\title{
EL POTENCIAL DE LOS TERRITORIOS DE LA ENERGÍA: BASES CONCEPTUALES DE LA PLANIFICACIÓN MUSEOLÓGICA DEL MUSEO NACIONAL DE LA ENERGÍA
}

\author{
The Potential of Energy Territories: Conceptual Bases \\ of Museum Planning for the National Energy Museum \\ O potencial dos territórios energéticos: bases conceituais \\ do planejamento museológico do Museu Nacional \\ da Energia
}

\author{
Esther APARICIO RABANEDO \\ Investigadora y museóloga \\ esther.aparicio@slowprojects.com
}

Fecha de recepción: 22/09/2020

Fecha de aceptación: 1/12/2020

RESUMEN: En el siguiente artículo se abordan algunas de las características conceptuales que están presentes en el proyecto de creación del Museo Nacional de la Energía (MNE), que se llegó a materializar solo parcialmente, sin su categoría nacional, en lo que hoy se denomina La Fábrica de Luz-Museo de la Energía en Ponferrada (León). Conceptos transversales como museo en red, territorio museo, parque museo, museología social y sostenibilidad permeabilizan todo el proyecto en una apuesta, no solo por crear un museo nacional, sino para intentar que fuese viable y contribuyera a los profundos retos que tiene la sociedad con respecto a la energía y al cambio climático. A pesar de que ese proyecto no se materializó en su totalidad, tanto el tema del museo, como los conceptos con los que se desarrolló su plan museológico, no sólo siguen estando vigentes, sino que se han consolidado con el tiempo, por lo que las comarcas de El Bierzo y Laciana, tan ricas en recursos, pueden seguir materializando proyectos basados en las mismas premisas, con 
formulaciones diferentes, pero con el mismo objetivo de contribuir al desarrollo de los territorios en los que se asienten dichos proyectos.

Palabras clave: territorio museo; museo en red; museos; museología social; turismo industrial.

ABSTRACT: In the following article, we discuss some of the conceptual characteristics present in the project focused on creating the National Energy Museum (NEM), which was partially materialized, without its national category in what is nowadays called La Fábrica de Luz (The Light Factory) - Museo de la Energía (Energy Museum) in Ponferrada (León). Transversal concepts such as network museum, territorial museum, park museum, social museology and sustainability, which impregnate the project as a whole. They were not only a bet in order to create a national museum but to try to make it feasible and contribute to the daring challenges that society has to face regarding energy and climate change. Even though this project did not materialize itself thoroughly, the museum topic and the concepts of the museology plan are not only valid at the moment but have also been consolidated over time: Therefore, the El Bierzo and Laciana regions, so rich in resources, can continue creating projects based on the same premises, with different formulations but with the same objective to contribute to the territories development in which these projects may be laid down.

Key words: territorial museum; network museum; museums; social museology; industrial tourism.

RESUMO: $O$ artigo a seguir aborda algunas das características conceituais presentes no projeto de criação do Museu Nacional da Energia (MNE), que apenas se materializou parcialmente, sem sua categoria nacional, no que hoje é chamado La Fábrica de Luz (A Fábrica de Luz) -Museo de Energía (Museu da Energia), em Ponferrada (León). Conceitos transversais, como museu em rede, território museu, parque museu, museologia social e sustentabilidade permeiam todo o projecto, em uma tentativa, não apenas de criar um museu nacional, mas de tentar torná-lo viável e contribuir para os profundos desafios que tem a sociedade em relação à energia e à mudança climática. Apesar de esse projeto não ter se materializado por inteiro, tanto o tema do museu, quanto os conceitos com os quais seu plano museológico foi desenvolvido, não apenas continuam em vigor, mas se consolidam ao longo do tempo, de modo que as regiões de El Bierzo e Laciana, tão ricas em recursos, podem continuar a materializar projetos com base nas mesmas premissas, com formulações diferentes, mas com o mesmo objetivo de contribuir para o desenvolvimento dos territórios em que esses projectos estão localizados.

Palavras chave: território museu; museu em rede; museus, museologia social; turismo industrial. 


\section{INTRODUCCIÓN}

En el año 2006 el Gobierno de España creó la Fundación Ciudad de la Energía (CIUDEN) con el objeto de promover la investigación y el desarrollo tecnológico en materia energética, potenciar los estudios ambientales relacionados con la energía, formar técnicos e investigadores en materia energética y crear y gestionar el Museo Nacional de la Energía (MNE), todo ello para generar un desarrollo social y económico en la Comarca de El Bierzo ${ }^{1}$. Este territorio se encontraba en declive por la paulatina desaparición de sus actividades económicas esenciales: la extracción de carbón y el funcionamiento de centrales térmicas de generación de electricidad. Se trataba de anticiparse y participar en la planificación, a medio y largo plazo, de la transición hacia otro modelo productivo, desarrollando proyectos coordinados, para amortiguar el impacto negativo del previsible cierre de las minas y el descenso del peso específico de las centrales térmicas instaladas en esta zona. Ambas actividades, que hasta entonces había sido fundamentales, tanto para El Bierzo como para la comarca aledaña de Laciana, han acabado desapareciendo una década después sin que dicha transición se haya producido.

\section{Punto de partida Conceptual de la creación del Museo nacional DE LA ENERGÍA}

Desde la década de los ochenta y, particularmente, desde los noventa del siglo XX, muchas ciudades industriales del entorno europeo están sufriendo las consecuencias de los grandes cambios económicos estructurales a nivel global, que les obligan a desarrollar planeamientos estratégicos diferentes a los utilizados hasta la fecha, para atraer inversión y actividad a sus regiones. En esa dinámica, acompañando dichos cambios y planeamientos, se comenzaron a introducir conceptos como el de ciudades creativas (Florida, 2009), la clase creativa (Florida, 2010) o la economía creativa, en la que Naciones Unidas identifica como sus principales motores: la tecnología, la demanda (de nuevos servicios y productos) y el turismo (ONU, 2010). Estas ciudades y sus territorios buscan la especificidad y visibilidad con respecto a otras de su entorno, por lo que en este caso la marca de ciudad y el marketing urbano son herramientas indispensables en el desarrollo de proyectos que pretenden transformar las dinámicas sociales, económicas y culturales. Se trata de particularizar estos espacios y prepararlos para "la economía de la experiencia", en la que el territorio desarrolla productos y servicios de valor añadido, que una parte de la población está dispuesta a disfrutar en muy diferentes formatos, donde las sensaciones que generan recuerdos significativos están muy presentes (Pine, Gilmore, 2000).

1. Orden ECI/2697/2006 de 2 de agosto, por la que se inscribe en el Registro de Fundaciones la Fundación Ciudad de la Energía-CIUDEN. BOE núm. 201, de 23 de agosto de 2006, página 30975. 
Teniendo en cuenta estas tendencias globales, entre la década de los noventa del siglo XX y principios del XXI se materializaron en España grandes proyectos arquitectónicos que trataban de crear iconos urbanos que tuviesen la suficiente potencia como para generar, directa o indirectamente, recursos socioeconómicos para la población en la que se asentaban. Muchos de estos proyectos tuvieron que ver con equipamientos culturales, de los que el Museo Guggenheim de Bilbao es un claro exponente de éxito, enmarcado en una planificación de reconversión de la ciudad muy profunda, pero también hubo grandes fracasos, motivados, entre otras cosas, por un pensamiento demasiado simplista que confiaba en que la mera existencia, de lo que se denominó "arquitectura estrella» o "arquitectura milagrosa» (Moix, 2010), tendría la capacidad de garantizar la visibilidad urbana, atraer turismo y reactivar la económica local. Así mismo, durante estas mismas fechas se produjeron cambios profundos en la manera de abordar los proyectos de creación y remodelación de muchos museos, que debían adaptarse a los nuevos usos y servicios, transformándose así en complejos museísticos, más allá de la existencia de salas donde se mostraban los objetos de las diferentes colecciones (Chinchilla, 2005). Esta confluencia entre bonanza económica y creación de museos como iconos de la modernidad y del desarrollo socioeconómico, tuvo su reflejo en la rápida implantación de centros de diferentes perfiles y tipologías. Tal y como lo avalan las estadísticas, de un total de 1137 museos existentes en España en el año 2005, 392 se habían creado desde los años noventa hasta esa fecha, lo que supone un 34,47\% del total (Chinchilla, 2005).

En este contexto, se apoyaron diversos proyectos de creación de museos nacionales en diferentes puntos del país, uno de los cuales fue el Museo Nacional de la Energía en El Bierzo (León). Habitualmente se considera que un museo nacional lo es porque ha sido definido así por legislaciones o decretos gubernamentales. Siendo un requisito imprescindible, no es suficiente para precisar, en la práctica, su aportación a la representación de valores, de realidades nacionales y su contribución a los fundamentos culturales de un estado (EuNaMus, 2012).

El impulso de este tipo de museos es poco habitual y, por la envergadura de un proyecto de estas características, se imponía reflexionar adecuadamente sobre lo que significaba crear un museo nacional en el siglo XXI, en un territorio periférico, alejado de los grandes núcleos de población y también de los flujos de turismo masivo. El hecho de partir de cero con este proyecto permitía dicha reflexión con un cierto grado de libertad, en la búsqueda de un modelo que conjugase el fin último de su creación en relación con el desarrollo socioeconómico de El Bierzo, con una voluntad de hacer planteamientos que permitiesen implantar un museo con un papel relevante para la sociedad española y que, a su vez, atendiese correctamente todas las funciones que tiene que cumplir una institución de este nivel. Por ese motivo, en un equilibrio entre el pensar y el hacer, se hizo una profunda reflexión que tuvo muy en cuenta el desarrollo del proyecto en fases, los diferentes enfoques de planificación, sin apostar necesariamente por copiar proyectos de otras ciudades, de hecho se eligió un modelo alejado de la «arquitectura 
milagrosa», se analizaron las tendencias globales que podrían ser aplicadas a este caso concreto y, sobre todo, conocer a fondo las características que iba a tener en su ubicación en El Bierzo, y más concretamente en Ponferrada, que era lo que primero que había que poner en marcha. Con respecto a este último aspecto, la inclusión del museo en una fundación de $\mathrm{I}+\mathrm{D}+\mathrm{i}$ relacionada con la energía y el cambio climático era especialmente interesante, ya que todos esos proyectos juntos podían generar sinergias e ir construyendo realidades que, a medio y largo plazo, pudiesen aportar conocimiento, unido a la atracción de inversiones, de talento y de actividades relacionadas con la temática.

Ahondando en lo que suponía la categoría de "Nacional» en el museo y su contribución a la cultura del país, se llegó a la conclusión que el tema de la energía y el cambio climático era de importancia vital para el futuro de la humanidad, visión que trasciende el ámbito nacional, por lo que el museo tenía la vocación de abordar estos temas con un marcado carácter universal. Sin dejar a un lado las especificidades nacionales e incluso locales, pero dando un peso específico a la transmisión de contenidos que aportasen valor, independientemente del lugar físico donde se encontrase el museo. Además, dado que existen colecciones energéticas de interés en diferentes puntos del país, que conviene conservar "in situ", y también atendiendo a la organización administrativa del Estado, el modelo del museo tendría que plantear una estructura en parte descentralizada. Se trataba de implantar un centro con una colección de interés para un funcionamiento adecuado en El Bierzo, con capacidad para liderar, coordinar o participar en proyectos conjuntos con otros museos o instituciones del país en los temas de su competencia, abriéndose a su vez a colaboraciones con otras instituciones internacionales.

Este museo que pretendía establecer y/o participar en redes, tenía la necesidad de contribuir a la existencia de una buena divulgación científica, con espacios para el conocimiento, la investigación y el ocio, con el objetivo de convertirse en un museo de referencia, tanto nacional como internacional, en su campo. Se trataba de estudiar en profundidad con qué herramientas se podía acercar la ciencia a la sociedad, empleando recursos comunicativos, expositivos y educativos, unidos a técnicas de movilización y participación ciudadana adaptadas a las necesidades de públicos muy diversos. En la visión del museo el centro de su política institucional no estaba en su colección, aunque esta fuese vital para su existencia, sino que se colocaba en el tema energético, en sus múltiples facetas, y en las personas. Se trata pues de un museo que tenía entre sus finalidades últimas, la creación de espacios de conocimiento y debate para incrementar "la ciudadanía científica" (Fischer, 2000), asumiendo la dificultad que supone la pretensión de incorporar la participación social de la ciencia, una tarea a largo plazo, como algo necesario en una sociedad compleja, donde el conocimiento y la apropiación social de la ciencia tiene un impacto en la calidad democrática de un país (Innerarity, 2011). En ese sentido el museo se encontraba muy en la línea de los aportes de la museología social o sociomuseología (Moutinho, 2012), cuyos postulados se centran en abordar el museo en clave de desarrollo y sostenibilidad, lo que en el caso del 
MNE era imprescindible para darle coherencia y credibilidad a su discurso museológico. No es posible proponer contenidos sobre energía y cambio climático sin que el concepto de sostenibilidad esté presente como aspecto transversal en todo el proyecto, y tampoco había muchos visos de conseguir el objetivo de contribuir al desarrollo local sin la visión de colocar a las personas en el centro de la política museística.

En resumen, la creación del museo estaba muy influida por las tendencias y herramientas que se manejaban en esta época: creación de imagen de ciudad o territorio, economía creativa y economía de la experiencia, pero también incorpora otras características que vertebran todo el proyecto: el concepto de red, de visión de contenidos en el eje local-nacional-transnacional, de participación social o creación de ciudadanía científica, postulados de museología social y sostenibilidad, así como generar un museo basado en el contenido multi e interdisciplinar, con objetos de la colección, con un valor al nivel de un museo nacional, pero cuya principal función era su capacidad de comunicación dentro del hilo conductor que se proponía en el plan museológico, no solo su conservación como piezas importantes.

\section{Museo NACiOnAL EN RED}

Si hay algo que define la sociedad contemporánea es su complejidad y las enormes transformaciones que se están produciendo, que afectan a todas las áreas de la vida, incluido el entramado de contactos entre las personas y de cómo éstas se relacionan con el mundo. En el centro de todo esto se encuentra el concepto de sociedad red, resultante de la relación entre la organización social, el cambio social y el tema tecnológico (Castells, 2006). Aunque el término no es nuevo, su afianzamiento tiene mucho que ver con la globalización y con estas tecnologías de la comunicación y la información, de las que Internet es la red por excelencia y las redes sociales actuales su máxima expresión.

El MNE no fue ajeno a esta realidad y desarrolló su modelo partiendo de la premisa de utilizar el concepto de red llevado más allá del ámbito tecnológico, aunque una parte de su diseño tenía que ver con este nuevo paradigma, para adaptarse, además, a la estructura descentralizada del Estado Español.

Para entender el lugar, en primer término, hay que emplazarlo en el espacio físico social en el que se encuentra ubicado, y, al mismo tiempo, en la red conceptual e imaginal en que se inserta, y que no necesariamente tiene que ver solo con proximidades físicas (Vergara, 2006, p. 155).

Por eso la organización en red va permeabilizando toda la conceptualización del museo, no se contempla como una instalación ubicada en un solo lugar y aislada. Muy al contrario, se definieron al menos cuatro dimensiones en las que se trabajaría por fases, desde el ámbito local al internacional, detallando los aspectos 
en los que la institución lideraría proyectos y otros en los que la fórmula adecuada sería establecer marcos de cooperación y coordinación con otras instituciones. Todo con el objetivo de abordar los diferentes aspectos de la energía y el cambio climático, que ya por entonces se vislumbraba como un tema de conocimiento fundamental para los ciudadanos.

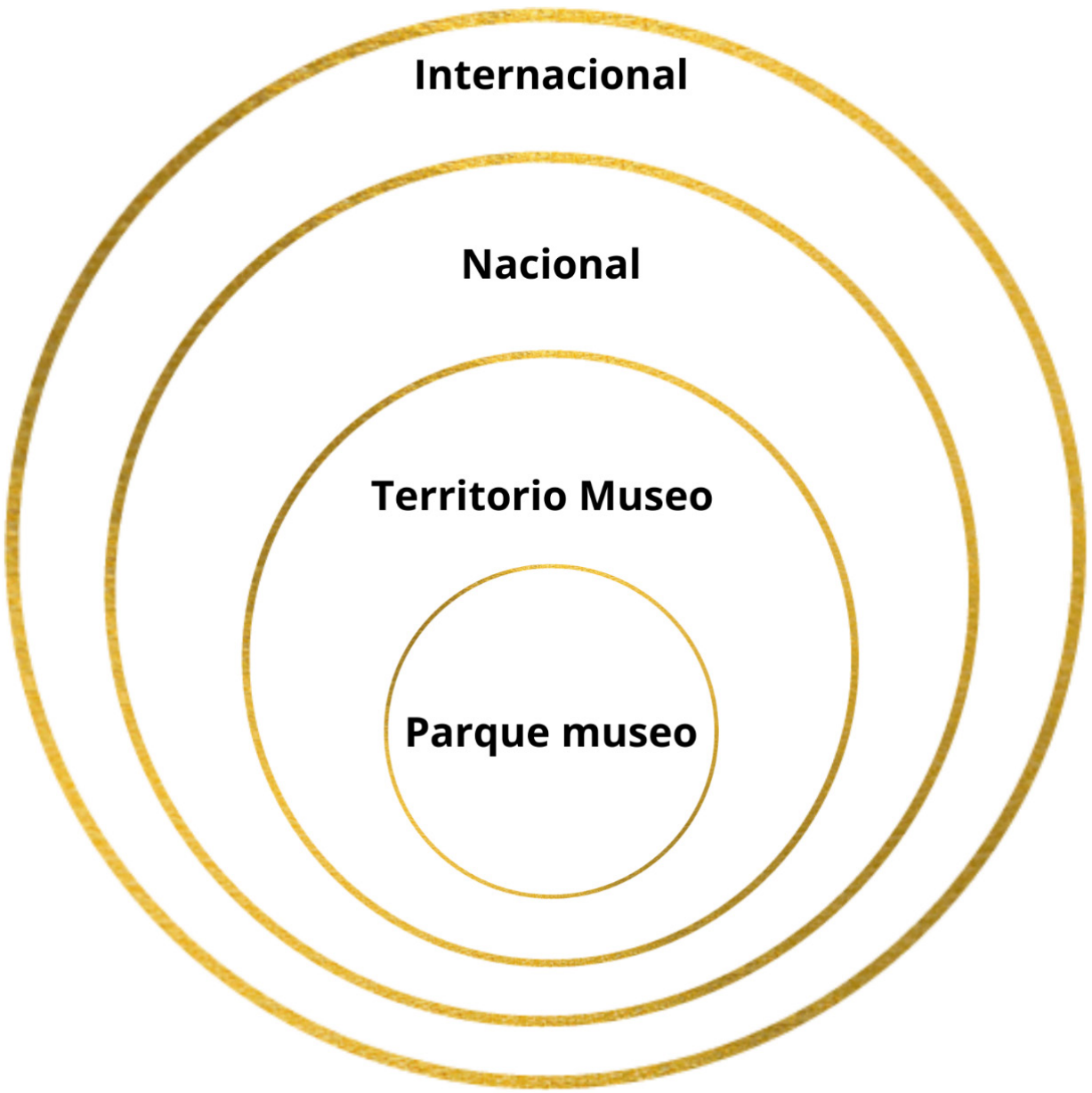

Imagen n. ${ }^{\circ}$ 1. Concepto de museo en red. MNE.

Como ya se indicó anteriormente, el museo se proyectó en la localidad de Ponferrada, dado que se contaba con la posibilidad de rehabilitar dos centrales térmicas ubicadas en la misma zona de la ciudad, donde además existían otros 
vestigios del pasado industrial de la ciudad. Así mismo, esta localización se ponía en relación con el territorio inmediato, las comarcas de El Bierzo y de Laciana, con sus instalaciones mineras y su patrimonio industrial que permiten la musealización e interpretación del territorio utilizando la energía como eje temático, para lo que se tomó como referencia el Museo Nacional de la Ciencia y de la Técnica de Cataluña (MNACTEC). Además, el proyecto seguía los planteamientos de Daniel Hiernaux, considerando la herencia minera como un punto de partida de la confrontación entre la herencia del pasado y el presente. Se consideraría el imaginario industrial patrimonial como «una creación de figuras/formas/imágenes, a partir de las cuales solamente puede uno referirse a algo» (Hiernaux, 2006, p. 29), que se inspira a su vez en la obra de Castoriadis, La institución imaginada de la sociedad.

Así, se subraya la importancia del componente humano. "Lo imaginario, por ende, está relacionado con procesos cognitivos y de memoria, sin que ello niegue su expresión en formas materiales. [...]» (Hienaux, 2006, p. 29). Además de reivindicar la existencia de nuevas temáticas y procesos más relacionados con el momento presente y sobre todo futuro, estableciendo así una conexión de todas las temporalidades. Razón por la cual se decidió que el museo tuviese un espacio, tanto en la planta de captura, como en la de almacenamiento de $\mathrm{CO}_{2}$, proyectos científico-tecnológicos impulsados por la Fundación Ciudad de la Energía.

Por otra parte, la historia energética de España ha producido objetos e instalaciones de valor cultural repartidos por toda la geografía nacional, además de la existencia de proyectos actuales que merece la pena que se divulguen como aportación al conocimiento colectivo. En este ámbito, el museo tenía la vocación de establecer relaciones en red con aquellos espacios que tuviesen una parte de sus contenidos centrados en los temas energéticos, con el objetivo de diseñar y compartir proyectos. En este sentido, se planificó pensando en la relación que mantendría con el Museo Nacional de Ciencia y Tecnología (MNCYT), con el que se pretendía establecer un marco de colaboración beneficiosa para ambas instituciones.

Por último, dado que una parte de los contenidos del museo tenía que ver con las sociedades contemporáneas y su relación con la energía y el cambio climático, el concepto de red se amplió al ámbito internacional, motivo por lo que se establecieron contactos y colaboraciones con instituciones de investigación y de divulgación, como el Instituto de Tecnología de Massachusetts (MIT) y otros centros, con los que en una primera fase de funcionamiento del museo se había diseñado que dispusiesen de un espacio en una de sus exposiciones permanentes, para mostrar a los visitantes temas punteros de interés, descubrimientos o innovaciones que pudiesen aportar los respectivos centros, de manera que el museo siempre estuviese actualizando parte de sus contenidos. 


\section{Parque Museo en Ponferrada como paisaje Cultural}

La ciudad de Ponferrada, como resultado de su pasado industrial más reciente, posee espacios relacionados con empresas dedicadas a la extracción de carbón y a la generación de electricidad, una amplia zona de la urbe que, una vez que las actividades cesaron, conserva infraestructuras sin actividad, a veces en muy mal estado, pero que son exponentes de una cultura industrial representada por elementos arquitectónicos que pueden volver a tener una vida en un nuevo contexto.

Se decidió la ubicación del museo en este sector de la ciudad, en dos centrales térmicas, Compostilla I que había pertenecido a Endesa, donde se colocaría la sede central del museo, y la central de la Minero Siderúrgica de Ponferrada (MSP), planteada como la sección histórico-antropológica del carbón. Ambos edificios, próximos entre sí, tienen en este mismo entorno elementos complementarios relacionados con el tema energético como: el poblado de trabajadores de Compostilla I, la central hidroeléctrica de la Fuente del Azufre, el río Sil e incluso la localización donde estuvo una gran montaña de carbón, lugar en el que se ubicaría el tercer edificio del museo: el Bosque del Carbonífero.

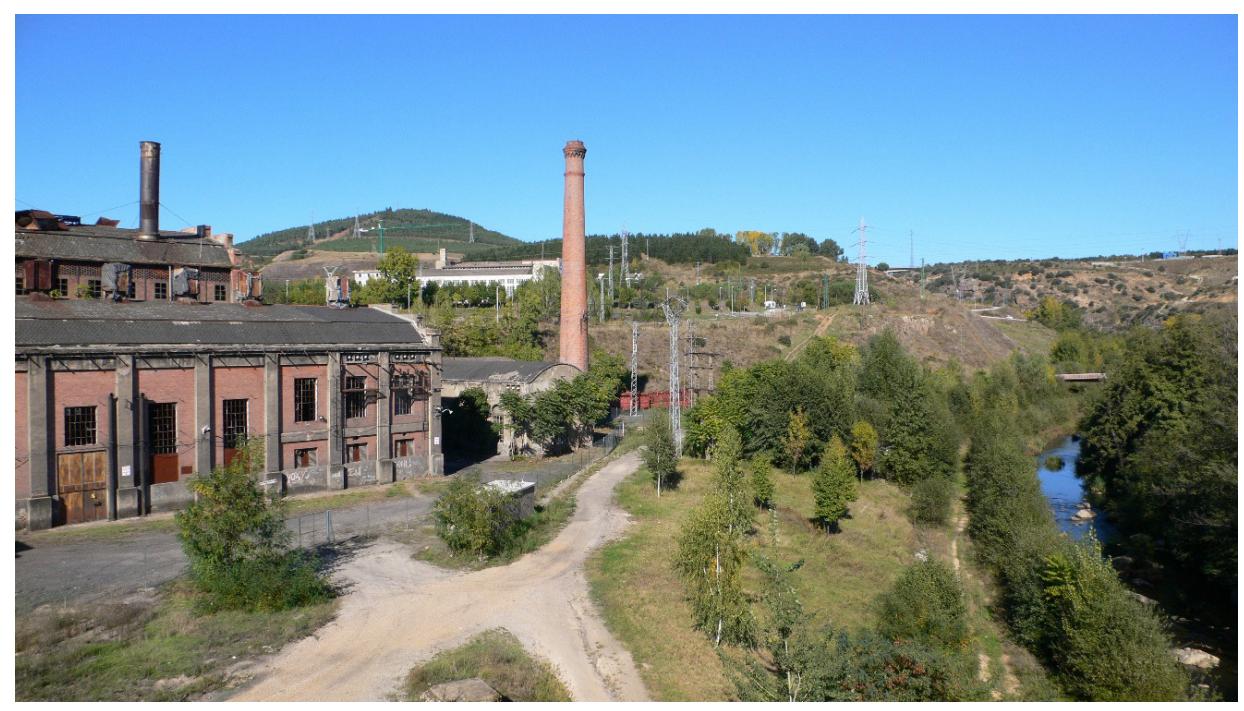

Foto n. ${ }^{\circ}$ 1. Elementos del parque museo en Ponferrada. La Fábrica de Luz en restauración en primer término. Foto: Antonio Muñoz Carrión.

Trabajar el proyecto utilizando los conceptos de parque museo y paisaje cultural, con una correcta interpretación patrimonial, a la vez que se incorporaban otros elementos, supuso una planificación de una enorme complejidad, para establecer un equilibrio entre las infraestructuras del pasado, su entramado sistémico 
que alude a procesos industriales, la aparición de intervenciones contemporáneas y el desarrollo urbanístico de la ciudad.

Como ya se ha indicado, por aquel entonces, muchas ciudades que trataban de sobresalir, estaban desarrollando potentes estrategias de marketing urbano, donde la cultura suponía un elemento importante como instrumento para mejorar la imagen de la ciudad y visibilizarse de manera singular, lo que habitualmente suele tener un impacto en la atracción de inversiones públicas y privadas para la zona. En este sentido, la existencia de un patrimonio cultural industrial, muy ligado a la identidad y a la memoria del lugar, lejos de ser un inconveniente, se podía convertir en un potente activo para proyectar una imagen original y diferente, lo que se convierte en una ventaja comparativa con respecto a otros territorios.

"Muchas veces, esas formas materiales vienen del pasado, representan relictos de otros tiempos históricos pero que sigue presentes y frente a los cuales las sociedades recrean nuevos usos, funciones o sentidos, o más bien se ven necesidades de hacerlo» (Lindon, Hiernaux y Aguilar, 2006, P. 12).

Así mismo, el modelo de parque museo, parecía ser una buena opción ya probada en otros lugares. Dicho modelo surge de la confluencia entre los centros de ciencias y los museos de ciencia y tecnología, así como de la incorporación de experiencias en patrimonio industrial y de los parques industriales, de los que existen exitosos ejemplos en otros países como Alemania o Bélgica. La peculiaridad de un parque museo es que en este modelo se pueden incorporar funciones patrimoniales, en este caso relacionadas con la energía, pero también otras funciones que tienen que ver con el ocio y el tiempo libre de los ciudadanos. En el caso de Ponferrada, todos los edificios museísticos y sus elementos complementarios, incluidas las áreas verdes, podían convivir en equilibrio con los usos residenciales, comerciales y otros servicios, lo que ofrecía grandes posibilidades para la creación de un potente y singular parque museo en esta zona urbana, que podría convertirse en una referencia tanto nacional, como internacional.

Dado el valor simbólico que tienen estos edificios y sus espacios anexos para este territorio, capaces de explicar uno de los períodos más importantes de su historia, se apostó por conectar los elementos con una correcta interpretación patrimonial, a la que se le añadieron expresiones contemporáneas propias de un museo moderno, de manera que se establecía un diálogo entre el pasado y el presente. No se trataba tanto de fosilizar un espacio, sino de trabajarlo desde el punto de vista de la transformación que va incorporando capas al mismo lugar, añadiendo, a su vez, la multitud de significados que tiene el propio concepto de paisaje, que siempre está en construcción (Mesquita y Pierotte, 2018).

En este sentido, el tratamiento del paisaje cultural estaba muy basado en la integración y la convivencia, que el espacio precisaba:

por un lado una interpretación objetiva que atienda a las características mesurables y propias del territorio que configura su base pero, por otro, precisa de esa visión más subjetiva del observador que lo contempla y que contribuye a su creación, en 
su más amplia acepción, a través de una experiencia sensitiva de la realidad (Alba, 2010, p. 447).

Para que esa integración funcionase, había, a su vez, que tener en cuenta que esas interrelaciones generan múltiples capas, tangibles e intangibles, ya que, como señala Contreras Delgado, "para la geografía el paisaje es mucho más que la superficie de la tierra. El paisaje cultural incluye los edificios en sus diversas formas (casas, fábricas, monumentos, barreras, etc.), pero, además de eso, el paisaje también incluye a las personas y las relaciones entre ellas. Los arqueólogos han propuesto la metáfora del iceberg para ejemplificar que el paisaje (visible) es solo una pequeña parte que sale a la superficie. Por tanto, la utilidad de los elementos visibles del paisaje es limitada, puesto que lo visible es solo la etapa final de una larga secuencia de desarrollo». (Contreras, 2006, p. 172).

Por tanto, era necesario investigar lo que Igor Kopytoff denomina «historia de vida de los objetos» para trabajar metodológicamente la cultura material.

Ello permite insistir en los cambios de estatus de los objetos en función de sus trayectorias. Estas modificaciones no son superficiales y hacen completamente ilusoria la cuestión de la "permanencia material» y por tanto la de la cultura material como "prueba objetiva». De esta manera, cada etapa está situada en un contexto que da un sentido diferente los objetos» (Julien; Rosselin, 2005, p. 43).

En un modelo como este, es esencial atender a la planificación urbana de la ciudad, ya que solo trabajando desde ahí se puede garantizar la convivencia de usos y la movilidad; además de la existencia del paisaje cultural. El MNE necesitaba un espacio más allá de sus edificios para colocar las áreas de aparcamiento, además de accesos claros y eficientes. Así mismo, era muy conveniente que existiesen espacios libres públicos inmediatos a los edificios, que contribuyesen, tanto a la valoración paisajística del entorno como a la acogida de visitantes e, incluso, mantener visible la sede central del museo desde muchos puntos de la ciudad, lo que contribuía a entender bien la trayectoria histórica de esta población. La planificación urbana existente no permitía ninguno de los requisitos esenciales para la inserción de un proyecto de estas características. Por lo tanto, fue necesario desarrollar un nuevo planeamiento para este sector de la ciudad que incorporó todas las características enunciadas en este apartado.

En definitiva, este modelo de museo no se centra en establecer el punto de atención sobre un edificio, sino que son varios conectados, con espacios verdes e incorporación de funciones nuevas, preservando el paisaje cultural en parte industrial y en parte de nueva creación, incorporando una correcta interpretación patrimonial a la que se añadían elementos museísticos contemporáneos. 


\section{El Museo nacional de la Energía como territorio museo}

Debido a su trayectoria histórica El Bierzo y Laciana conservan instalaciones relacionadas con la minería, el sector energético y el ferroviario. La energía como actividad que forma parte de su pasado, que en ese momento todavía estaba en marcha y que se pretendía que siguiese teniendo un papel en su futuro con nuevos proyectos energéticos. En relación al museo, se trabajó con el concepto de territorio museo, basado en principios de desarrollo sostenible, en su doble vertiente: como "gran museo al aire libre, abierto y habitado en continuo movimiento y transformación» (Miró, 2009), a la vez que incorpora una estructura organizativa, con una estrategia de interpretación del territorio elaborada, basada en la planificación y la búsqueda de acuerdos con las partes implicadas en el desarrollo territorial (Miró, 2009).

Un territorio vertebrado por un eje temático potente tiene más posibilidades de consolidar, tanto una imagen externa clara, como el desarrollo de proyectos que tengan que ver con la identidad local, en este caso la energía, lo que es un factor positivo en la futura sostenibilidad social de un museo que está muy vinculado a la trayectoria del territorio. Máxime cuando la idea era seguir desarrollando actividades productivas y de investigación e innovación en estas mismas comarcas, para generar una especie de "territorio de la energía», un clúster a largo plazo, que unía el I+D+i, con la divulgación científica y la posible atracción de empresas del sector a estas comarcas y el desarrollo de otras actividades como el turismo, sector este último al que se le dio la máxima importancia, ya que sin una buena oferta turística en estas comarcas, el museo tendría muy difícil su viabilidad.

No se trata tanto de crear espacios museísticos por todo el territorio, sino más bien de desarrollar una oferta de ocio cultural y ecológico, en la medida de lo posible, integrando bienes patrimoniales, la vida cotidiana y aquellas actividades productivas que pudiesen formar parte del conocimiento público. De manera que, visitantes y residentes, fuesen capaces de aprovechar lo que les ofrecía el lugar en clave, en este caso energética, observando y experimentando "in situ" tanto los avances como los grandes dilemas que existen en torno a este tema y que el museo quería mostrar. Así mismo, esto exige una estrategia de interpretación del territorio en la que un museo de categoría nacional podría tener un papel destacado, en fases posteriores, a través del consenso con los actores locales y la planificación, de manera que fuese posible establecer unos límites claros del territorio (Padró y Miró, 2002), en este caso muy coincidente con el marco geográfico de El Bierzo y Laciana, con unas acciones coordinadas, en la que la colaboración con actores locales era indispensable, para desarrollar proyectos complementarios que fuesen variados, atractivos y cuya pertenencia a una red mayor que la local le pudiese dar visos de viabilidad, sobre todo económica. 


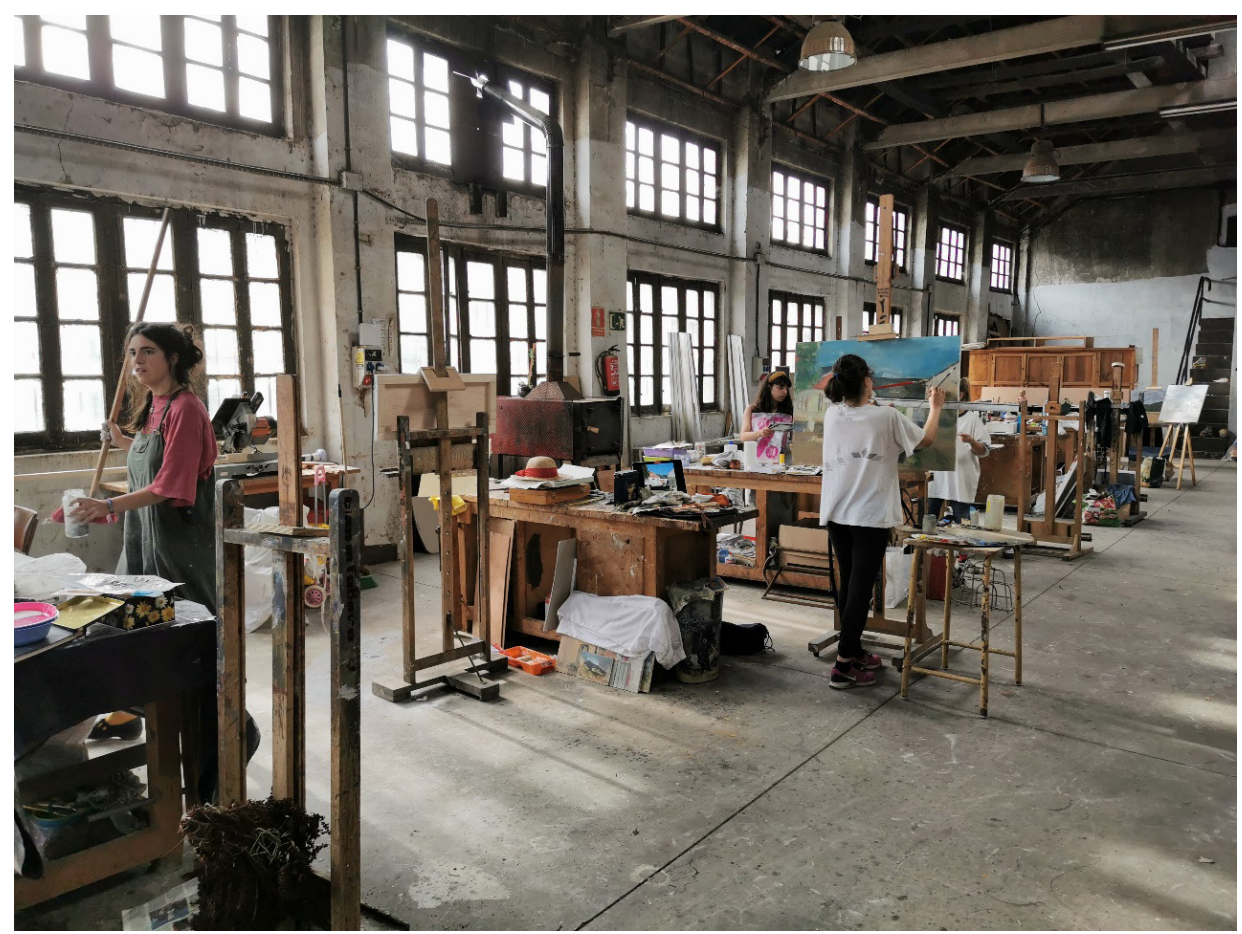

Foto n. ${ }^{\circ}$ 2. CIAN-Fabero. Residencias de verano. Talleres del Pozo Viejo. Foto: Antonio Muñoz Carrión.

En definitiva, se trataba de aprovechar la oportunidad de la instalación del MNE en las comarcas de su influencia local para liderar o participar en proyectos que caminasen en una misma línea, teniendo siempre en cuenta que "La clave de la gestión patrimonial pasa por introducir los principios de participación, autonomía y descentralización; y por la diversificación de las fuentes y formas de financiación, tanto públicas como privadas». (Padró y Miró, 2002, p. 79). Favoreciendo la toma de decisiones conjunta entre representantes políticos, profesionales afectados y sociedad civil, a través de los principios de corresponsabilidad y subsidiariedad.

Por esta razón, en un modelo así, el MNE tenía que acercarse al territorio y estudiar no solo el patrimonio existente con inventarios y otros instrumentos, sino también la situación de las actividades, sobre todo de ocio y turismo que pudiesen generar sinergias, y en el caso de que no existiesen, apoyar aquellas iniciativas que fuesen positivas para que las comarcas se dinamizasen, contribuyendo a sustentar un museo que necesitaba, no solo crear unas infraestructuras, sino también poner en marcha un plan de gestión que hiciese viable su funcionamiento. En este sentido, 
la Fundación Ciudad de la Energía comenzó a trabajar en temas turísticos y otros relacionados con el desarrollo rural, era necesario apoyar, crear o mejorar productos y servicios que contribuyesen a que el MNE tuviese mucha visibilidad y poder de atracción a las comarcas con ofertas integradas, coordinadas y singulares. De ahí el incentivo a la creación de empresas de ocio y turismo, la instalación o apoyo a pequeños alojamientos, el impulso de "La Mirada Circular» como ruta por la comarca de EL Bierzo, el proyecto de Enoturismo o la creación de la sociedad anónima público-privada "Turismo Contigo" comercializadora de servicios y productos, entre otros muchos proyectos. Todos ellos impulsados con el objetivo de conseguir una oferta, sobre todo turística, cultural y educativa, con posibilidades de supervivencia y generación de oportunidades reales para estas comarcas.

\section{LA FÁBrica de LuZ-Museo de Energía: PuerTa de ENTRADA Al TERRITORIO MuSEO}

Esta antigua central térmica, convertida en museo, iba a ser la sección histórico-antropológica del MNE. Es la única parte del proyecto que se puso en funcionamiento en julio de 2011 y que, a día de hoy, mantiene su actividad con el nombre de Fábrica de Luz-Museo de Energía. Fue reconocida con el Premio Europa Nostra en el 2012 y nominada al mejor museo europeo del año 2015 en los premios EMYA (European Museum of the Year Award). Es una instalación pensada en relación con otras que se diseñaron en lo que iba a ser el parque museo en Ponferrada, razón por la cual cuenta con oficinas y espacios multiusos muy limitados.

En el proyecto del MNE, esta central se programó como la parte del museo en Ponferrada más vinculada a las comarcas de El Bierzo y Laciana, una lanzadera para el territorio que presenta; una puerta de entrada al mismo (Padró y Miró, 2002). Con la energía como hilo conductor, que forma parte del pasado cercano y de la identidad de las comarcas y sus gentes. Por esa razón, en lo que se refiere a contenidos, coexisten en el este museo varias temáticas que se van entrelazando y que en algunos puntos del museo comparten el mismo espacio. Se trataba de mostrar tanto la importancia del carbón y la generación de energía para El Bierzo y Laciana, como el transporte ferroviario del carbón y el funcionamiento de una central térmica, así como las formas de vida en relación a la memoria del trabajo relacionado con las dos empresas históricas en clave nacional (ENDESA y MSP); además de atender en el futuro las funciones nacionales encomendadas a su sección.

La visión con la que se planteó la recuperación de este espacio era, por una parte, al igual que en los demás espacios del parque museo, rescatar una zona degradada de la ciudad y ponerla a disposición no sólo del visitante, sino, sobre todo, de la población local, razón por la cual los espacios exteriores son abiertos y recuperados para la ciudad. Por otra parte, el hilo conductor que vertebra todo este proyecto, desde la rehabilitación, la restauración del espacio exterior y la museografía, fue la preservación de lo que se denomina «espíritu del lugar», que es: 
el conjunto de elementos materiales (edificaciones, sitios, paisajes, rutas, objetos) e inmateriales (recuerdos, historias, documentos escritos, rituales, festivales, conocimientos tradicionales, valores, texturas, colores y olores, entre otros); es decir, los elementos físicos y espirituales que otorgan significado, valor, emoción y misterio al lugar (Icomos, 2008).

En este sentido, La Fábrica de Luz trata de preservar la ambientación basada en la autenticidad del espacio que permite al visitante trasladarse a otro tiempo. Recuperando los elementos existentes para entender la secuencia industrial «in situ", posibilitando, en la medida de lo posible, la experiencia sensorial y el estímulo de la curiosidad por ese complejo mundo y por las personas que trabajaron en él; la memoria del trabajo. Combinando el conocimiento racional con la parte más subjetiva, ya que «Los sentidos no sólo transmiten información para el juicio del intelecto, también son medios de inflamar la imaginación y de articular el pensamiento sensorial» (Pallasmaa, 2006, p. 47). Es desde ahí, que se propicia una experiencia de visita, "los objetos crean formas de sentir que deben abordarse a través de los sentidos, en lugar de como «textos» para ser leídos o simples "signos» visuales para ser decodificados. En otras palabras, los objetos tienen biografías sensoriales y sociales». (Classen y Howes, 2006, p. 200).

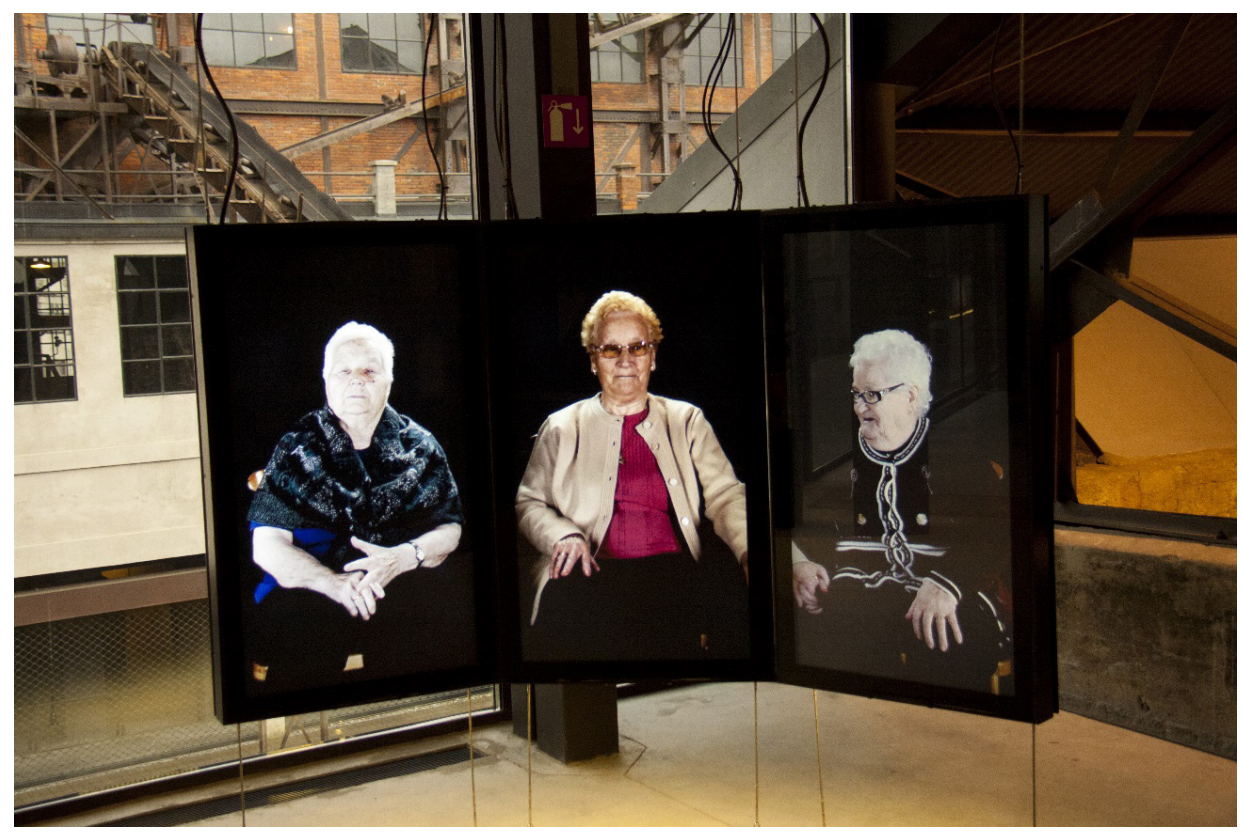

Foto n. ${ }^{\circ}$ 3. Fábrica de Luz. Mujeres mineras. Foto: Antonio Muñoz Carrión. 
En cuanto a la memoria oral, los testimonios de los trabajadores, no solo de la central, sino también de las actividades mineras y ferroviarias, tienen un peso especial, contribuyendo a humanizar los espacios de trabajo, con la presencia de pantallas con testimonios en primera persona, en una relación pretendidamente directa con los visitantes.

\section{Museología SOCIAL Y SOSTENIBILIDAd EN EL MNE}

La planificación museológica del MNE se encuentra muy ligada a los postulados de la museología social, "de enriquecimiento del patrimonio y de la memoria colectiva dentro de los museos, a través de la participación activa de las comunidades en el proceso de apropiación cultural democrática y de interés común para toda la sociedad» (Stoffel, 2012, p. 8), visión en la que el museo tiene un papel de mediador cultural entre el patrimonio, el territorio y la comunidad.

Según la museología social o Sociomuseología, los museos deben aspirar a tener una dimensión global, donde exista un mantenimiento del patrimonio natural y cultural local, como contribución a un ámbito superior y con una mirada puesta en aquellas tendencias que afectan a la humanidad. Por ese motivo la visión del MNE, en su interpretación de lo "Nacional", no pierde nunca de vista todos los aspectos internacionales, lo que supone estar muy abiertos a las aportaciones que se puedan hacer desde otros lugares y sociedades, además de darle cabida a las situaciones que se estén viviendo en cualquier parte del mundo. Por eso el plan de contenidos del museo tenía una tendencia a tratar temas locales, pero sobre todo universales, considerando la diversidad social existente con respecto a los temas energéticos y medioambientales. Siguiendo con un enfoque social, con el convencimiento de que el museo debía servir a muy diferentes públicos, para que todos ellos encontrasen algo de su interés, se trabajaron esos mismos contenidos, sobre todo en las exposiciones permanentes del museo central en Ponferrada, desde el relato o historia que se quiere transmitir, por lo que la museografía tenía una estructura argumental coherente y narrativa. No era un museo de módulos independientes, ni tampoco de espacios disciplinares (Aparicio, 2019).

Así mismo, por su gran compromiso con el territorio y su visión muy centrada no tanto en el público de forma individualizada, sino en potenciar la comunidad, se hizo un especial hincapié en ir más allá de un museo en un edificio y abarcar un territorio en el que el museo se implanta de manera descentralizada, como ya se ha indicado, con procesos de participación social y de creación de ciudadanía científica, pero también de revalorización de la identidad local. Con los que, en algunos casos, se pretendía llegar a lo que en museología social se denomina "sistema abierto e interactivo» (Hernández, 2012, p. 26) en el que el museo desarrolla posibilidades de participación e incorpora a aquellas personas interesadas y proactivas en la mejora de su entorno. Con esta visión a largo plazo, la comunicación del MNE siempre expresaba su objetivo último de construir un museo 
«de» $\mathrm{y}$ "con» las personas, con una filosofía de museo inclusivo, que combate la desigualdad y la discriminación, tratando, además, de desdibujar las fronteras entre la institución y el público. Así se entendía la creación de comunidad, en un sentido amplio, dado que una persona alejada físicamente podía formar parte de la misma, siempre que el museo se hubiese convertido en un espacio significativo para ella. Se trataba de crear y dinamizar espacios de investigación, conocimiento, educación, ocio y entretenimiento, no solo de fomentar un museo como un lugar exclusivamente para el consumo turístico.

En lo que respecta a la identidad local, hay que destacar que el patrimonio industrial en estas comarcas, tiene la peculiaridad de que muchas personas que han estado vinculadas a la actividad están vivas, por lo que la visión era incorporarlas, en la medida de lo posible, no sólo como informantes y testimonios que se recopilan en los archivos del museo, sino también como colaboradores activos desde las fases iniciales del proyecto. Se trataba de trabajar unos temas y bienes culturales, con un valor simbólico que trasciende lo meramente económico, era necesario potenciar ese valor para ir generando conciencia y apoyo social, dado que las cualidades y potencialidades de este tipo de patrimonio no suelen ser evidentes para la población; en este caso tampoco lo fue.

El proyecto consideraba la presencia de lo subjetivo en todos los elementos del patrimonio industrial local. Entre los habitantes de la zona está arraigado un imaginario colectivo que se relaciona con una memoria y una representación del espacio y del tiempo que comunican por si solas, con la mediación de sus protagonistas. Se incorpora lo subjetivo como elemento de valor, que supone un aporte que le da densidad al proyecto y se huye de la intervención exclusiva en las formas materiales, con la consiguiente pérdida de memoria colectiva. (Hiernaux, 2006).

Las voces de estos protagonistas, en todos los niveles: ingenieros, obreros, capataces, oficinistas, directivos, así como sus familias, que vivieron indirectamente el progreso familiar y que fueron receptores del paternalismo empresarial. Testimonios que aportan percepciones y relatos tanto biográficos, como técnicos, acerca de qué significó depender en algún momento de su ciclo de vida de los beneficios de la industria y de cómo realizaban su trabajo, que muchas veces no coincidía exactamente con lo que aparecía en las instrucciones fabriles. Todos ellos son portadores de significados, de sensibilidades, de memoria y, generalmente, están muy dispuestos a resignificar, desde el presente, el valor que entonces tuvo la irrupción del modo de vida industrial en su estilo de vida. En esta parte de la planificación se impulsaron diferentes proyectos que tenían una vertiente en parte de investigación y conocimiento y, en parte, de concienciación social en torno a la identidad local, como por ejemplo, la colección de fotografías «Imágenes para el Recuerdo", que se recogieron con testimonios en las dos comarcas, la creación de un equipo de inventario que tenía múltiples funciones, una de ellas establecer vínculos con la población local, la recogida sistemática de testimonios 
audiovisuales o la colaboración de antiguos trabajadores de MSP en la museografía de La Fábrica de Luz-Museo de Energía.

Así mismo, los trabajos que tenían como objetivo la concienciación y la participación social también se encaminaron a potenciar la comunidad con respecto al medio ambiente y la cultura científica, resaltando la importancia de la relación de las personas con su entorno, que valorasen su patrimonio natural para que fuesen ellos mismos los encargados de protegerlo. Esta es la razón por la que las primeras actuaciones de este de museo tuvieron que ver con la puesta en marcha de su área educativa, que desarrollaba su trabajo en múltiples sitios de las comarcas, mucho antes de tener un entorno físico para desarrollar sus actividades. Además de los esfuerzos por comunicar el avance del proyecto con exposiciones, las visitas a las obras o la elaboración de vídeos donde se contaba cómo se hace un museo y personas de la comunidad aportaba lo que ellos creían que tenía que contener dicho museo. Exponente de esta visión de concienciación social fue el "Proyecto Ríos» dedicado a la conservación de los ecosistemas fluviales a través del voluntariado y la participación social, proyecto que comenzó en Cataluña y que funcionaba en red, al que el museo dedicó recursos para la dinamización social, lo que se tradujo en unos buenos resultados, ya que año a año se fue aumentando el número de voluntarios involucrados en este proyecto. En esa misma línea, el proyecto "La Mirada Circular", que se inició con una clara vocación de trazar un sendero turístico, que transitase las montañas de El Bierzo, pero en el que se desarrollaron actividades para potenciar el conocimiento del medio por parte de los habitantes del territorio.

Todos estos planteamientos presentes en el MNE, fueron objeto de una planificación que contemplaba la exigencia de trabajar a largo plazo de manera sistemática, con programas educativos y de comunicación, apoyados por otros de inventario e impulso de diferentes productos turísticos, con el objetivo de ir generando una conciencia colectiva del valor de lo existente en el territorio y su uso, incorporando los tres aspectos fundamentales de la sostenibilidad: desarrollo económico, inclusión social y equilibrio medioambiental, siendo este último el eje que lo vertebra todo. (Vilches, Macias y Gil).

El concepto de sostenibilidad es complejo, sistémico y el resultado de una convención, lo que significa que es necesario dotarlo de significado en la actividad en la que se aplique, en este caso un museo (Aparicio y Azuara. 2015), que tenía la necesidad de abordar este tema para no caer en la incoherencia, pero que debía hacerlo compatible con otros criterios para el buen funcionamiento del proyecto, lo que supuso un profundo proceso de reflexión sobre lo que significa ser un museo sostenible, a la vez que muchas de las decisiones de gestión tenían en cuenta este tema para la toma de decisiones. No se trataba de ser sostenible o no, sino de ver en qué grado era posible serlo, cumpliendo con todos los requisitos de funcionalidad y poder de convocatoria, aportando todas las soluciones que hubiese en ese momento, sobre todo, para manejar el consumo energético, que en un museo de estas características suele ser alto. 


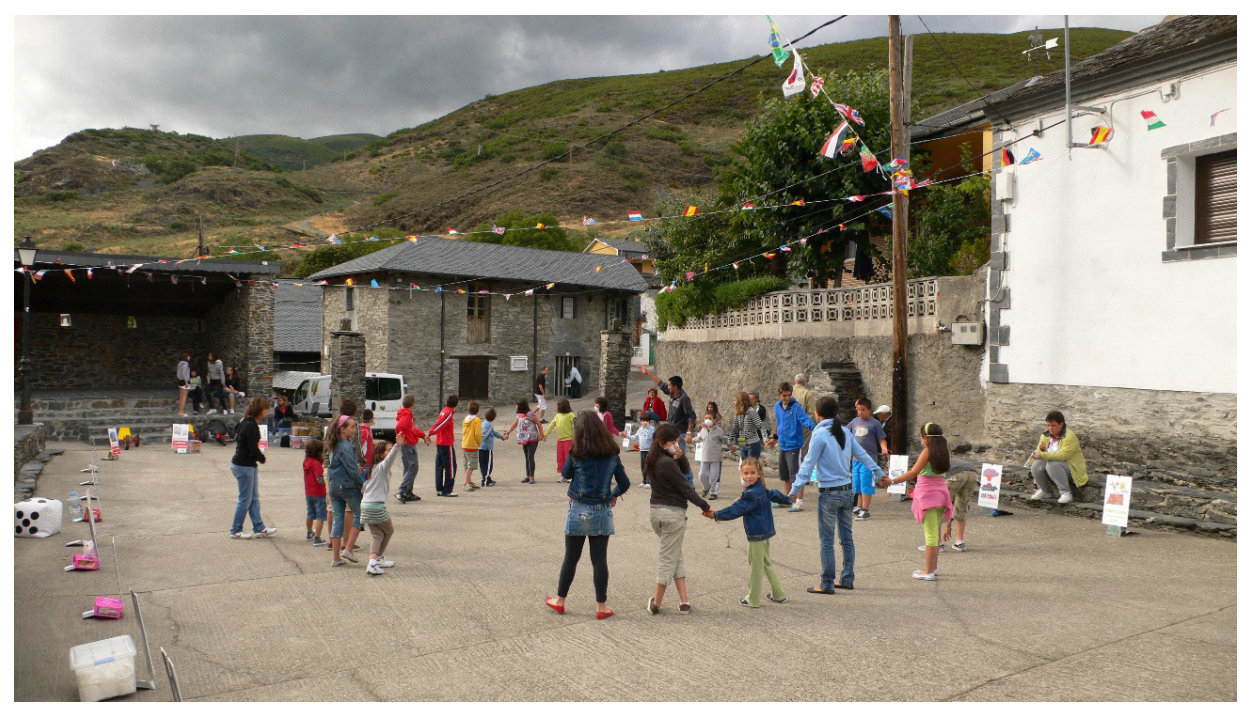

Foto n. ${ }^{\circ}$ 4. Actividades educativas en el territorio. Foto: Antonio Muñoz Carrión.

\section{CONCLUSIÓN}

El Museo Nacional de la Energía fue un proyecto que no se llevó a término en su totalidad. En este tipo de iniciativas se precisa una planificación en fases, que suelen abarcar más de un período electoral, por lo que se necesita de un gran consenso político para su correcta implantación; consenso que en el caso de este museo nunca se alcanzó. En el año 2012, las obras del edificio central del museo se encontraban paralizadas por falta de acuerdo, debido a las reivindicaciones económicas de la empresa constructora. Así mismo, el patente avance de la crisis económica recomendaba reformular el proyecto y seguir avanzando con los mismos conceptos y planes de gestión, pero con diferentes estrategias, que comportasen una menor inversión que la obra que se estaba ejecutando, lo que podía asegurar el avance del proyecto y también su viabilidad. Ese mismo año, con el cambio de gobierno, la dirección de la Fundación Ciuden decidió seguir adelante con el contrato de rehabilitación paralizado, con una gran reducción en el alcance del proyecto, pero sin que se presentase un plan de gestión para la puesta en marcha de ese museo, cuya obra terminada sigue sin tener un uso a día de hoy. Por lo tanto, en relación al proyecto original, se paralizaron todos los planes existentes, se abandonó la idea, al menos de momento, de crear un Museo Nacional de la Energía, se mantuvo la actividad de la Fábrica de Luz, que se había inaugurado en el año 2011 y se han desarrollado algunas actuaciones urbanísticas alrededor de dicho museo para mejorar sus accesos. 
A pesar de que este proyecto no se realizó en su totalidad, las bases conceptuales que se han venido desgranando en el presente artículo, muchos de sus criterios y planes de gestión, se encuentran aún más vigentes que cuando se plantearon. Por lo que, con una buena labor de planificación y de coordinación de agentes públicos y privados, sería posible desarrollar proyectos en estos territorios de la energía que aportarían impulso en un momento de transición tan delicado como el actual, en el que se han parado muchas actividades y no terminan de aparecer, con la suficiente fuerza, otras nuevas.

El Bierzo y Laciana, una vez que las empresas mineras y eléctricas han cesado su actividad, cuentan con una gran cantidad de bienes, que podrían ser utilizados de manera coordinada entre los diferentes agentes para configurar una oferta, que coloque a estas dos comarcas como territorios atractivos para su visita, conocimiento e, incluso, para otras actividades empresariales. Existen ya instalaciones en marcha, como La Fábrica de Luz o el Museo del Ferrocarril en Ponferrada, proyectos con buenas perspectivas de futuro, como la cuenca de Fabero o los posibles trabajos para dinamizar el ferrocarril entre Ponferrada y Villablino, el denominado Ponfeblino, además de la labor que está desarrollando la Cátedra de Turismo Sostenible y Desarrollo Local de la UNED en relación con estos temas. Todo ello en un entorno en el que se tienen que desarrollar los Convenios de Transición Justa (CTJ), impulsados por el Gobierno de España, en las comarcas afectadas por el cierre de las minas y de las centrales térmicas de carbón. Planes de acción territorial integral que tienen como objetivo mantener y crear actividad y empleo en dichos territorios, que pueden ser una buena oportunidad para convertir el patrimonio industrial de la zona en un activo.

El potencial del patrimonio industrial como recurso no sólo turístico, sino también educativo, cultural, de ocio e, incluso empresarial, se ha consolidado en estos años. En la actualidad, ya existen numerosos proyectos en funcionamiento en todo el mundo, que avalan el interés del público, tanto turistas como residentes, por este tipo de instalaciones y paisajes, que en muchas ocasiones se usan como museos, pero que también admiten otros usos y actividades variadas. En este contexto, estos territorios de la energía pueden ser un buen exponente en España de las posibilidades de generar actividad, utilizando las infraestructuras del pasado para seguir ofreciendo oportunidades de desarrollo para el futuro.

\section{REFERENCIAS BIBLIOGRÁFICAS}

Alba, M. I. (2010). Paisajes de la memoria. hacia una definición del paisaje industrial como paisaje cultural. VCongreso Conservación del Patrimonio Industrial y de la Obra Pública en España. Patrimonio Industrial y Paisaje (pp. 447-452). Ferrol: Cicees.

Aparicio, E. (2019). La museografía en el proyecto de creación del Museo Nacional de la Energía en Ponferrada (León). Revista de museología, (76), pp. 59-74. 
Aparicio, E., Azuara, J. A. (2020). Museos y sostenibilidad: argumentos para la convergencia. En F. Vidargas (ed), Antología. Patrimonio mundial (pp. 106-121). México: Instituto Nacional de Antropología e Historia.

Arroyo, R. (2011). La sociedad de ensueño del turismo. Anuario turismo y sociedad, 12, pp. 17-26. https://dialnet.unirioja.es/servlet/articulo?codigo=3914392

Castells, M. (ed). (2006). La sociedad red: una visión global. Madrid: Alianza.

Classen, C., Howes, D. (2006). The museum as sensescape: western sensibilities and indigenous artefacts. En E. Edwards et al. (eds.), Sensible objects: colonialism, museums and material culture (pp. 199-222). Oxford: Berg publishers.

Chinchilla, M. (2005). Una mirada profesional sobre la creación de museos. Museos.es: Revista de la subdirección general de museos estatales, (1), pp. 48-59.

Contreras, C. (2006). Paisaje y poder político: la formación de representaciones sociales y la construcción de un puente en la ciudad de monterrey. En A. Lindón, M. A. Aguilar y D. Hiernaux (coords.), Lugares e imaginarios en la metrópolis (pp. 171-186). Barceloa: Anthropos.

Fischer, F. (2000). Citizens, Experts and the Environment: The politics of local knowledge. Durham and London: Duke university press.

Florida, R. (2009). Las ciudades creativas. por qué donde vives puede ser la decisión más importante de tu vida. Barcelona: Paidós.

Florida, R. (2010). La clase creativa: la transformación de la cultura del trabajo y el ocio en el siglo XXI. Barcelona: Paidós.

Hernández, F. (2012). Una aproximación a la definición de sociomuseología. Revista de museología, (53). pp. 15-29.

Icomos. Declaración de Quebéc sobre la preservación del espíritu del lugar. Quebéc. 4 de octubre de 2008. https://icomos.es/wp-content/uploads/2020/01/13.declaraci\%c3\%93nde-quebec.pdf

Innerarity, D. (2011). La democracia del conocimiento. por una sociedad inteligente. Barcelona: Paidós.

Jensen, R. (1999). The dreams society: how the coming shift from information to imagination will transform your business. Mcgraw-hill Education.

Julien, M-P., Rosselin, C. (2005). La culture matérielle. Paris: La découverte.

Lindo, A., Aguilar, M. A., Hiernaux, D. (2006). De la espacialidad, el lugar y los imaginarios urbanos: a modo de introducción. En A. Lindón, M. A. Aguilar y D. Hiernaux (coords.), Lugares e imaginarios en la metrópolis (pp. 9-25). Barcelona: Anthropos.

Mesquita, Z., Pierotte, O. (2018). O patrimônio industrial como elemento da paisagem cultural e a paisagem cultural conformando o patrimônio industrial: uma relação conceitual. Geosul, Florianópolis, 33,(69) (dossiê: geografia cultural), pp. 66-87. http:// dx.doi.org/10.5007/2177-5230.2018v33n69p66

Moix, L. (2010). Arquitectura milagrosa. hazañas de los arquitectos estrella en la España del Guggenheim. Barcelona: Anagrama.

Miró, M. (2009). Museo abierto y territorio museo, nuevos conceptos para la interpretación territorial del patrimonio cultural. https://manelmiro.com/2009/07/01/museo-abiertoy-territorio-museo-nuevos-conceptos-para-la-interpretacion-territorial-del-patrimoniocultural/

Moutinho, D. (2012). Nueva museología de ayer, sociomuseología hoy. Revista de museologia, (53), pp. 30-34. 
Onu. (2010). Economía creativa: una opción factible de desarrollo. https:/unctad.org/es/ docs/ditctab20103_sp.pdf

Padró, J., Miró, M. (2002). Gestión creativa y desarrollo territorial. Retos del patrimonio en el siglo XXI. Periférica internacional. Revista para el análisis de la cultura y el territorio, 1(3), pp. 60-82. https://revistas.uca.es/index.php/periferica/article/view/1076

Pallasmaa, J. (2006). Los ojos de la piel. La arquitectura y los sentidos. Barcelona: Gustavo Gili.

Pine II, B. J; Gilmore, J. H. (2001). La economía de la experiencia. el trabajo es teatro y cada empresa es un escenario. Barcelona: Granica.

Stoffel, A. M. (2012). De qué hablamos cuando hablamos de sociomuseología. Revista de museología, (53), pp. 8-14.

Vergara, A. (2006). Espacio, lugar y ciudad: etnografía de un parque. En A. Lindón, M. A. Aguilar y D. Hiernaux (coords.), Lugares e imaginarios en la metrópolis (pp. 149-160). Barcelona: Anthropos.

Vilches, A., Macias, O., Gil, D. (2020). La transición a la sostenibilidad un desafío urgente para la ciencia, la educación y la acción ciudadana. Temas clave de reflexión y acción. Documentos de trabajo de Iberciencia 1. OEI, Iberciencia y Junta de Andalucía. https://www.miteco.gob.es/es/ceneam/recursos/pag-web/transicion-sostenibilidad. aspx 